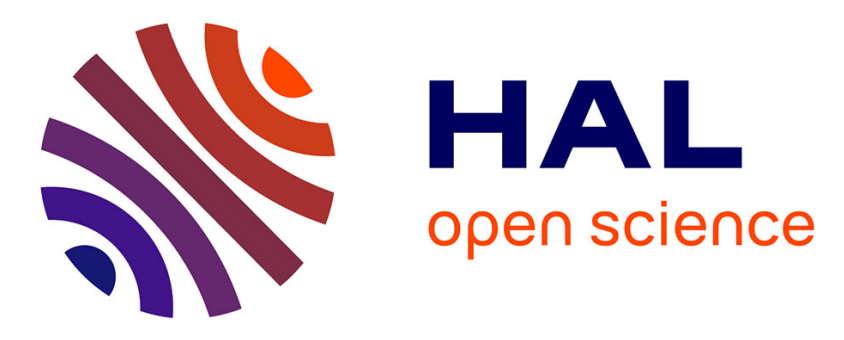

\title{
Metabolomic Nuclear Magnetic Resonance Studies at Presymptomatic and Symptomatic Stages of Huntington's Disease on a Drosophila Model
}

Marylène Bertrand, Martine Decoville, Herve Meudal, Serge Birman, Celine Landon

\section{To cite this version:}

Marylène Bertrand, Martine Decoville, Herve Meudal, Serge Birman, Celine Landon. Metabolomic Nuclear Magnetic Resonance Studies at Presymptomatic and Symptomatic Stages of Huntington's Disease on a Drosophila Model. Journal of Proteome Research, 2020, 19 (10), pp.4034-4045. 10.1021/acs.jproteome.0c00335 . hal-02968233

\section{HAL Id: hal-02968233 https://hal.science/hal-02968233}

Submitted on 20 Nov 2020

HAL is a multi-disciplinary open access archive for the deposit and dissemination of scientific research documents, whether they are published or not. The documents may come from teaching and research institutions in France or abroad, or from public or private research centers.
L'archive ouverte pluridisciplinaire HAL, est destinée au dépôt et à la diffusion de documents scientifiques de niveau recherche, publiés ou non, émanant des établissements d'enseignement et de recherche français ou étrangers, des laboratoires publics ou privés. 


\title{
Metabolomic NMR studies at presymptomatic and symptomatic stages of Huntington's disease on a Drosophila model
}

Marylène BERTRAND ${ }^{1 *}$, Martine DECOVILLE ${ }^{1,2}$, Hervé MEUDAL ${ }^{1}$, Serge BIRMAN ${ }^{3}$, Céline LANDON ${ }^{1}$

\author{
${ }^{1}$ Center for Molecular Biophysics, CBM, UPR 4301, CNRS, Rue Charles SADRON, F- \\ 45071 Orléans cedex 02, France \\ ${ }^{2}$ University of Orléans, 6 Avenue du Parc Floral, F-45100 Orléans, France \\ ${ }^{3}$ GCRN team, Brain Plasticity Unit, UMR 8249, CNRS, ESPCI Paris, PSL Research \\ University, F-75005, Paris, France
}

\section{ABSTRACT}

Huntington's disease (HD) is an inherited neurodegenerative disorder, for which diagnostic development and discovery of new therapeutic targets are urgently required. In this study, a model of HD in Drosophila melanogaster has been used to identify metabolic biomarkers at presymptomatic and symptomatic stages of the disease. The pan-neuronal expression of a pathogenic fragment of the human Huntingtin (HTT) protein containing a 93-repeat polyglutamine expansion (Httex1p Q93) in transgenic flies induces a neuropathology with several characteristics of the human disease. The discriminant 
metabolites between the diseased flies and their controls were identified by ${ }^{1} \mathrm{H}$-nuclear magnetic resonance (NMR) and orthogonal partial least squares discriminant multivariate analysis (OPLS-DA). The experiments carried out with 10-day-old flies allowed us to identify a set of 10 biomarkers of the presymptomatic stage: $\mathrm{NAD}^{+}, \mathrm{AMP}$, fumarate, asparagine, dimethylamine, $\beta$-alanine, glutamine, succinate, glutamate and ethanol. Remarkably, the experiments conducted with 16-day-old flies, when the symptoms of the disease were present, highlighted a different set of 6 biomarkers: phosphocholine, ethanolamine, 2-oxoglutarate, succinate, pyruvate and acetate. Our results provide a better understanding of the metabolic impairments in a widely used HD model and demonstrate that metabolism perturbations change dramatically during the development of the disease.

KEYWORDS: Huntington's disease, neurodegenerative diseases, Drosophila, metabolomics, NMR, presymptomatic 


\section{INTRODUCTION}

Huntington's disease (HD) is an autosomal dominant inherited neurodegenerative disorder caused by a mutation in the huntingtin (HTT) gene located at band $4 p 16.3$ on chromosome $4 .{ }^{1}$ Patients developing HD have an expanded CAG repeat in the first exon of the gene that includes from 36 to 121 repeats, ${ }^{2}$ leading to polyglutamine expansion in the Huntingtin protein (HTT). Depending on the length of the CAG repeat and of other genetic and environmental conditions, symptoms usually appear between the ages of 30 to 50 . These symptoms include motor dysfunction, psychiatric disturbances and cognitive decline. The patients also develop other symptoms such as muscle atrophy, impaired glucose tolerance and weight loss. There is currently no treatment to stop or reverse the course of the disease, which generally leads to death within 10 to 30 years after emergence. ${ }^{3}$ However, some medications can limit the clinical defects. ${ }^{4,5}$

At the molecular level, the mutant Huntingtin protein (mHTT) accumulates abnormally. Misfolded fragments of this protein containing the polyglutamine expansion form cytoplasmic aggregates and nuclear inclusions throughout the brain, ${ }^{6}$ leading to progressive neuronal toxicity. The disruption of several cellular mechanisms has been reported, including alterations in gene expression and transcription, protein folding and degradation, synaptic signaling, and energy metabolism..$^{7-9}$ To better understand the causes and consequences of the disease, different studies have been carried out on humans and animal models to discover metabolic biomarkers of $\mathrm{HD},{ }^{10}$ most of them focusing on the brain, either post mortem ${ }^{11,12}$ or in vivo. ${ }^{13,14}$ Some metabolomic analyses have also been conducted in biological fluids such as plasma ${ }^{15,16}$ or cerebrospinal fluid. ${ }^{17}$ 
HD animal models have been developed in various organisms such as mouse, ${ }^{18-20}$ rat, ${ }^{17,21,22}$ sheep ${ }^{23}$ or invertebrates such as the fruit fly Drosophila. ${ }^{24-26}$

Here we selected Drosophila as this model organism is well-established to study human diseases. Drosophila are easy to handle and many approved genetic tools are available for transgenesis and gene expression / inactivation in specific cell and tissue types. The Drosophila genome is 25 times smaller than the human genome, but about $75 \%$ of the genes involved in human diseases have orthologues in Drosophila. Although its brain appears to be simple compared to mammals, Drosophila display complex behaviors such as learning and memory, sleep or courtship. ${ }^{25}$ In addition, its nervous system is composed of various types of neurons (dopaminergic, serotonergic, glutamatergic, GABAergic ...) and glia as in vertebrates. Numerous models of neurodegenerative diseases, including Parkinson's or Alzheimer's diseases, have been developed in Drosophila. ${ }^{27} \mathrm{HD}$ models have been described by overexpressing either in the eyes, neurons or glial cells, amino terminal fragments of human HTT containing various tracts of polyQ, or full-length human mutant HTT (128Q). ${ }^{25-28}$ These models summarize the characteristic symptoms of HD, namely protein aggregation, neurodegeneration, behavioral defects and reduced lifespan.

In this report, we describe the changing metabolic profile of a pan-neuronal Drosophila model of HD. The purpose of our study was to identify biomarkers of HD using ${ }^{1} \mathrm{H}$-nuclear magnetic resonance (NMR) at two stages of the disease, presymptomatic and symptomatic, using 10-day-old and 16-day-old HD flies, respectively. We show that the metabolic signature of the disease is significantly different at these two stages. 


\section{EXPERIMENTAL PROCEDURES}

\section{Drosophila Culture}

The fly stocks were maintained at $22^{\circ} \mathrm{C}$ on a standard medium (per liter: $90.25 \mathrm{~g}$ cornmeal, $82.5 \mathrm{~g}$ dry yeast, $10.75 \mathrm{~g}$ agar and $37.5 \mathrm{~mL}$ of a $10 \%$ solution of methyl-4hydroxybenzoate in ethanol). Crosses were performed at $25^{\circ} \mathrm{C}$ on standard medium. The F1 progeny was collected each day and maintained at $26^{\circ} \mathrm{C}$ on Nutri-Fly medium (Dominique Dutscher, Brumath, France). Drosophila lines were: $w^{1118}$ used as wild-type controls, elav-Gal4 (elav $\left.{ }^{155}\right)^{29}$ and UAS-Httex1p Q93. ${ }^{30}$ To express Httex1p Q93 in neurons, elav-Gal4 virgin females were crossed with UAS-Httex1p-Q93 males (HD flies) (Figure 1). As controls, we crossed elav-Gal4 virgins with $w^{1118}$ males (Gal4 controls) and $w^{1118}$ virgins with UAS-Httex1p Q93 males (UAS controls). Only F1 progeny females were used for metabolite analysis in this study. The analysis was carried out in females specifically because they are larger than males and heterozygous for the X-linked elavGal4 insertion. 


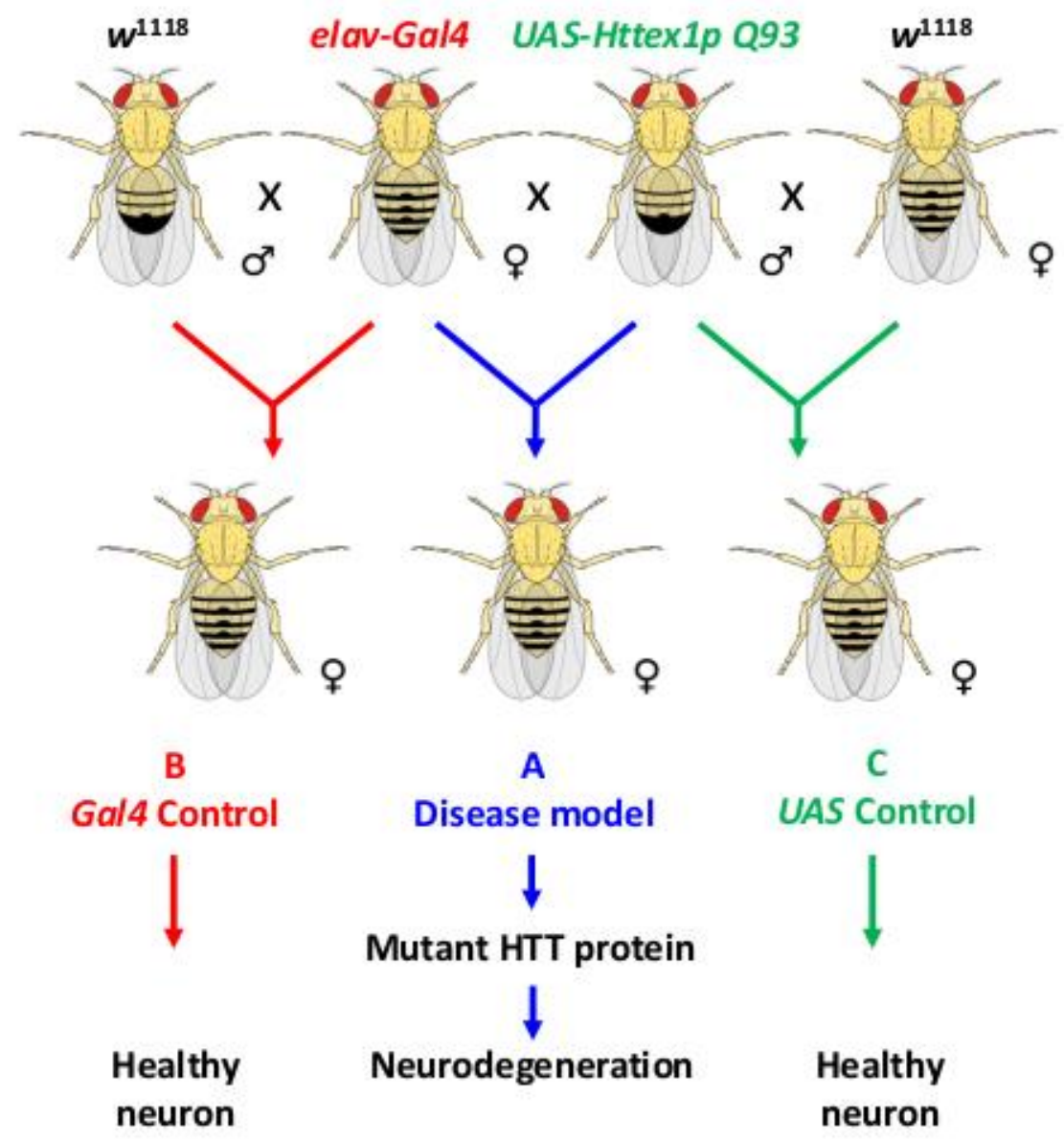

Figure 1. Fly crossing scheme used to generate the three sets of samples. Disease model ( $\mathrm{A}, \mathrm{HD}$ flies in blue), Gal4 control (B, in red) and UAS control (C, in green). Only $\mathrm{F} 1$ progeny females of these crosses were used for this study.

\section{Sample Preparation}

Eight to twelve samples were prepared for each batch of HD flies or controls. In order to have a good signal / noise ratio in NMR spectra, five female Drosophila were used per sample. They were flash frozen in a 1-mL microtube by immersion in liquid nitrogen. Flies were then manually crushed with a suitable conical stick in the microtube and $400 \mu \mathrm{L}$ of 
ice-cold $50 \%$ acetonitrile was added as described in previous studies. ${ }^{31,32}$ The mixture was shaken with a vortex, sonicated during $5 \mathrm{~min}$ in an ice-cold bath and then centrifuged for 10 min at $15,300 \mathrm{~g}$ at $5^{\circ} \mathrm{C}$. The supernatants $(350 \mu \mathrm{L})$ were transferred to new tubes. Acetonitrile was evaporated in a SpeedVac for 30 minutes. The tube contents were freezedried overnight and stored at $-80^{\circ} \mathrm{C}$.

For NMR analyses, $300 \mu \mathrm{L}$ of an ice-cold $50 \mathrm{mM}$ phosphate buffer $(\mathrm{pH} 7.4)$ in $\mathrm{D}_{2} \mathrm{O}$ containing $7.5 \mu \mathrm{g} / \mathrm{L}$ 3-(trimethylsilyl)-propionic-2,2,3,3-d4 acid sodium salt (TSP-D4) was added to the lyophilized samples. After homogenization with vortex, centrifugation for 10 min at $15,300 \mathrm{~g}$ at $5^{\circ} \mathrm{C}, 250 \mu \mathrm{L}$ of the supernatant were transferred to a 3-mm NMR tube, and kept at $5^{\circ} \mathrm{C}$.

\section{NMR Acquisition and Processing}

The NMR measurements were performed at $25^{\circ} \mathrm{C}$ on a Bruker Avance-III HD 700 spectrometer, equipped with a 5-mm HCN triple resonance cryoprobe. Bruker's TopSpin software 3.2 package was used for the acquisition and processing of NMR spectra. ${ }^{1} \mathrm{H}$ NMR spectra were acquired using a cpmgpr1d pulse program, which attenuates broad signals from high-molecular-weight components (D1 = 4s; 128 scans; spectral width: 11 ppm; experimental time: $14 \mathrm{~min})$. The water signal was suppressed by presaturation of the water peak. For assignment purposes, bidimensional COSY, TOCSY and ${ }^{13} \mathrm{C}-\mathrm{HSQC}$ spectra were acquired (see Figure S1 in supporting information). The first spectrum was manually phased. The following spectra were automatically phased and referenced to TSP resonance at $0.0 \mathrm{ppm}$ and their baselines were adjusted. A moderate local baseline

correction $^{33}$ and a peak alignment of the NMR spectra ${ }^{34,35}$ was performed with NMRProcFlow open source software (https://www.nmrprocflow.org/ ${ }^{36}$ ). The NMR spectra 
( 2 zones excluding the water peak's region from 4.86 to $4.75 \mathrm{ppm}$ ) were segmented into variable buckets using the "intelligent bucketing" method ${ }^{37}$ of the NMRProcFlow software. The spectral regions from $1.38-1.25 \mathrm{ppm}$ and $0.93-0.85 \mathrm{ppm}$ (signals of residual lipids) and the spectral regions having a Signal / Noise Ratio (SNR) lower than 3 were excluded. All NMR spectra were processed with nmrprocflow in exactly the same way so that they could be compared reliably, and were exported into a unique data matrix.

\section{Statistical Analysis}

This data matrix was further split into three sets of data, allowing three analyses: i) the presymptomatic analysis compares the 10-day-old fly samples, carrying the disease (HD flies) or not (controls); ii) the symptomatic analysis compares the 16-day-old fly samples, carrying the disease or not and; iii) the change analysis compares the HD flies at the two stages of the disease.

Each set of data was imported in Workflow4Metabolomics 3.0 Galaxy online infrastructure for the statistical analysis achievement (https://galaxy.workflow4metabolomics.org/38). Before the statistical analyses, the buckets in each NMR spectrum were normalized to the total sum of the spectral intensity. For each set of data, multivariate as well as univariate statistical analyses were performed to check the quality and the dispersion of samples, the quality of variables, and to find the discriminant variables between the groups.

\section{Multivariate Statistical Analyses}

OPLS-DA (orthogonal partial least-squares discriminant analysis) was used as multivariate analysis in order to find discriminant variables of two groups of samples. ${ }^{39}$ Three parameters were followed to evaluate the quality of OPLS-DA models: R2X and 
R2Y to quantify the goodness-of-fit and Q2Y to quantify predictive accuracy of the model. Permutation tests (100 cycles) were conducted to assess the robustness. Discriminant variables were defined by a threshold of variable importance of projection (VIP) coefficients in the prediction greater than 1, derived from the OPLS-DA model. This method offers the advantage to remove disturbing variation.

\section{Univariate Statistical Analyses}

Through the Workflow4Metabolomics online infrastructure ${ }^{38}$ univariate statistical analysis were performed, in order to check the significance of the variables. The factor of interest being qualitative with 2 levels, t-test with $p$-value significance threshold of 0.05 was performed and $p$ and $q$-values were calculated. ${ }^{40}$ The $q$-value gives the expected positive false discovery rate obtained by rejecting the null hypothesis for any result with an equal or smaller q-value. For metabolites with several peaks, common or average $p$ and $q-$ values of the different peaks are given.

\section{Metabolite Identification}

The NMR peaks highlighted by VIPs upper than 1 were then assigned. The corresponding metabolites were identified from their ${ }^{1} \mathrm{H}$ and ${ }^{13} \mathrm{C}$ chemical shifts, with databases such as $\mathrm{HMDB},{ }^{41} \mathrm{BRMB}^{42}$ and a home-made database. For unambiguous identifications, when needed, some reference compounds were directly added to the samples to identify precisely the affected peaks of interest. It is worth mentioning that metabolites displaying several peaks in the ${ }^{1} \mathrm{H}-\mathrm{NMR}$ spectrum were retained only when all the peaks were present and when all or most of the peaks were discriminant.

\section{Discrimination performance of biomarkers}


Using the open source MetaboanalystR software ${ }^{43}$ (https://www.metaboanalyst.ca) prediction models and ROC (Receiver Operating Characteristic) curves were performed to identify a set of metabolites capable of classifying unknown samples as HD or control samples with high sensitivity and specificity. A matrix composed of all samples (10 and 16-day-old HD and control flies) and of the 46 variables / peaks of the discriminating metabolites was created and ROC curves were constructed to select the best metabolite combination. A model with 15 metabolites (one variable by metabolite) was created. Finally, the performance of the model was evaluated with ROC curve and logistic regression analyses were performed with selected variables and samples.

\section{RESULTS}

Nervous system expression of the first exon of human HTT with 93 CAG repeats (Httex1p Q93) has been extensively characterized in previous works as a reliable HD model in Drosophila. ${ }^{30,44-49}$ Here we used elav-Gal4 as a driver, allowing expression of the polyglutaminated protein in all neurons in adult flies which causes reduced viability and neuronal degeneration in adult flies. Because Httex1p Q93 was not only expressed in the brain but also in the ventral nerve cord and peripheral neurons with this driver, metabolites were extracted from the entire Drosophila and not only from the head. In this study, we performed NMR experiments on 10- and 16-day-old HD flies and on their two controls: 10-day-old flies are at a presymptomatic stage, which means that they do not show a significantly higher death rate than the controls, while the survival of 16-day-old HD flies is reduced to about $50 \%$ of that of the controls, indicating that they have reached a fully 
symptomatic stage. ${ }^{45} \mathrm{~A}$ typical NMR spectrum obtained with 16-day-old HD flies is shown in Figure 2.

To eliminate the contribution of each transgene to modifications of the metabolite patterns, two controls were processed in parallel. The first one corresponds to flies carrying only the elav-Gal4 transgene (Gal4 control) and the second one to flies carrying only the UASHttex1p Q93 transgene (UAS control). For each experiment, statistical analysis was performed by comparing HD flies with Gal4 controls then with UAS controls, and finally HD flies with the associated Gal4 and UAS controls. Only VIPs common to the three comparisons were retained for further analysis. This method excludes the variables which are discriminant for one type of controls only and keeps the most reliable variables. 

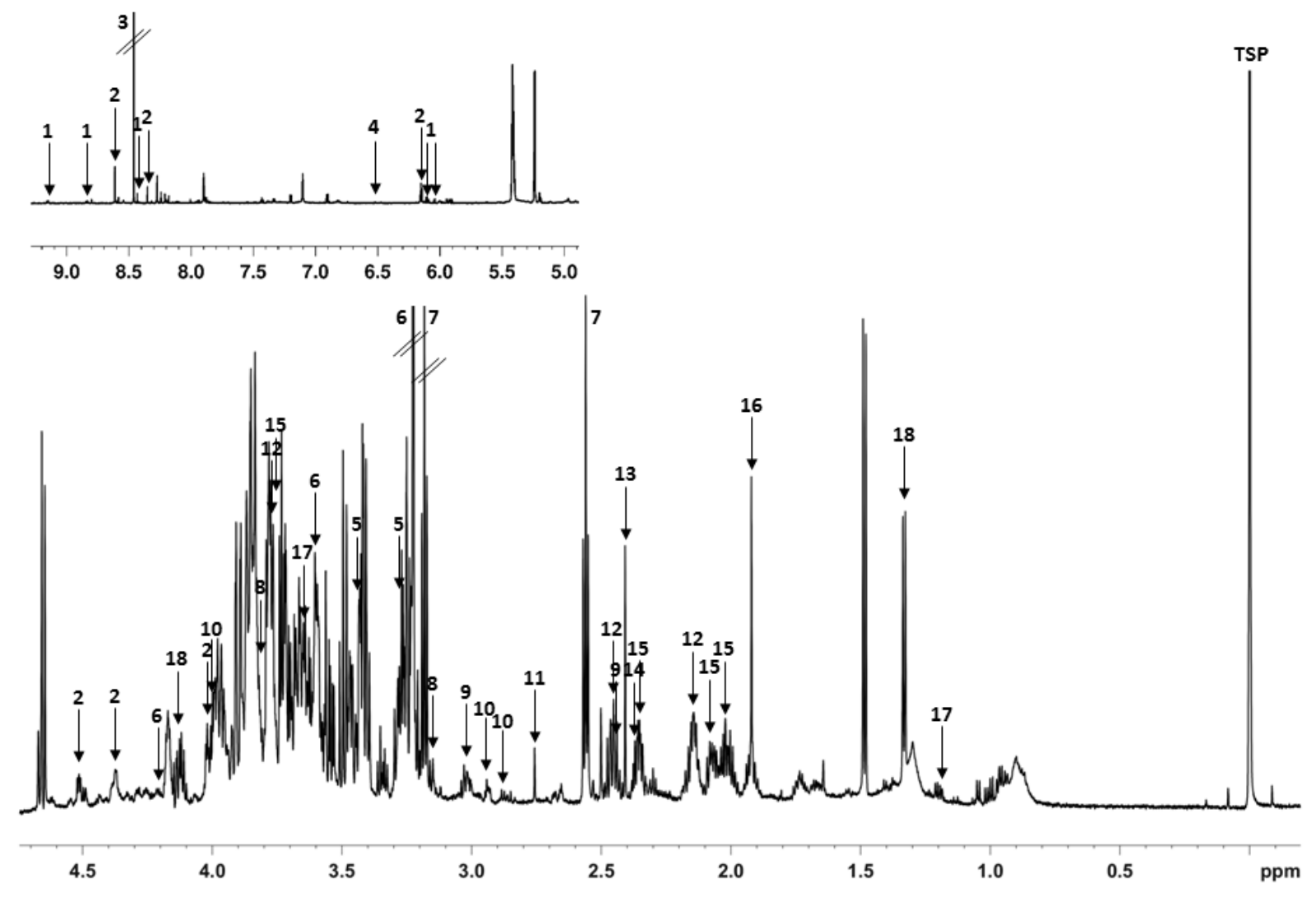

Figure 2. Example of ${ }^{1} \mathrm{H}-\mathrm{NMR}$ spectrum with the identified metabolites. This spectrum was obtained with 16-day-old HD flies and is representative of spectra obtained at all stages and in control flies. 1: $\mathbf{N A D}^{+}$nicotinamide adenine dinucleotide -2 : AMP adenosine monophosphate - 3: Formate - 4: Fumarate -5 : Taurine -6 : Phosphocholine - 7: $\beta$-Alanine - 8: Ethanolamine - 9: 2-Oxoglutarate ( $\alpha$ ketoglutarate) - 10: Asparagine - 11: Dimethylamine - 12: Glutamine - 13: Succinate -14: Pyruvate - 15: Glutamate -16: Acetate -17: Ethanol -18: Lactate.

Presymptomatic stage biomarkers 
An OPLS-DA model was used to find the discriminant metabolites between the 10-dayold HD flies and the controls (Figure 3 ). Only discriminant variables (VIPs $>1$ ) from OPLSDA and showing confidence interval at the $95 \%$ level were retained: i) 157 variables were identified between HD flies and the associated two controls, ii) 228 variables between HD flies and Gal4 controls, and finally iii) 189 variables between HD flies and UAS controls. All the OPLS-DA analyses performed led to a good or excellent separation of the groups and had large $\mathrm{R} 2 \mathrm{X}(0.80 ; 0.77$ and 0.72 , respectively) and $\mathrm{R} 2 \mathrm{Y}(0.99 ; 0.98$ and 0.96 , respectively) which indicated high reproducibility and a good fitting of the model to the data. The Q2Y parameters, calculated by cross validation were close to $1(0.93 ; 0.93$ and 0.94 , respectively) which are indicative of the high predictivity of the models. The discriminant variables of the three OPLS-DA were compared to each other using a Venn diagram and the 79 variables common to the three groups were retained for further analysis. 

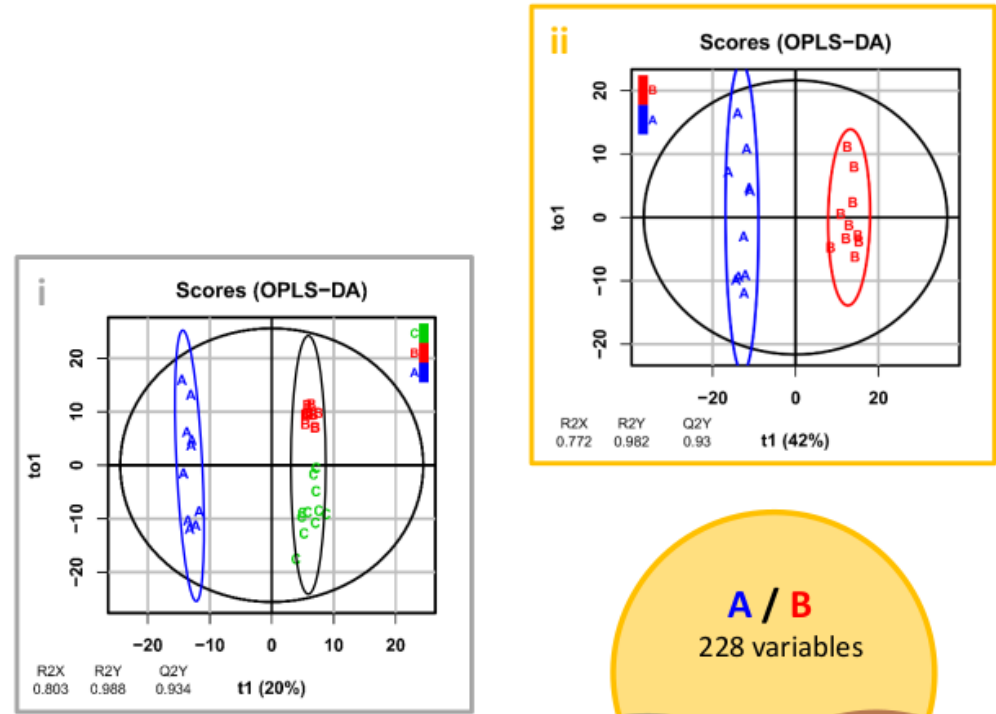

10-day-old flies

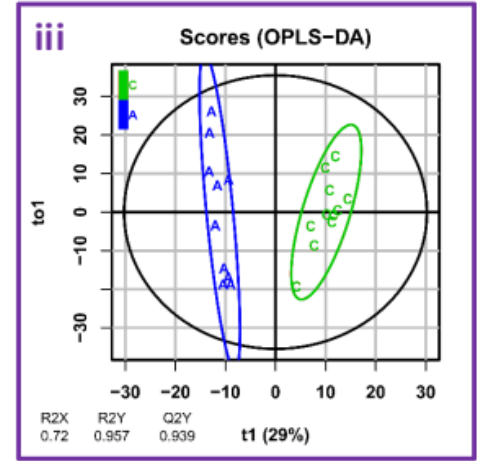

79 variables $>1$

Figure 3. Discriminant variables at the presymptomatic stage (10-day-old flies). OPLSDA analyses performed between the three groups of samples of 10-day-old flies. (i): OPLS-DA analysis for discrimination of HD flies and sum of Gal4 and UAS controls; (ii): OPLS-DA analysis for discrimination of HD flies and Gal4 controls; (iii): OPLS-DA analysis for discrimination of HD flies and UAS controls. A Venn diagram shows the 79 variables common to the three sets of samples. A: HD flies (in blue), B: Gal4 controls (in red) and C: UAS controls (in green).

The metabolites identified for the 10-days-old flies from the 79 discriminant variables are presented in Table 1 (VIP score of each of the discriminant metabolites is displayed in the Figure S2 as supporting information). All the q-values are very low, which means that the 
identified metabolites are statistically highly significant. At this stage of the disease, all the identified metabolic biomarkers are lower in HD flies than in controls.

\begin{tabular}{|c|c|c|c|c|c|c|}
\hline 10-day-old & $\begin{array}{c}{ }^{1} \mathrm{H} \text { chemical shift } \\
\text { in ppm } \\
\text { (multiplicity) }\end{array}$ & Assignment & q-value & $p$-value & & \\
\hline \multirow[t]{16}{*}{ NAD $^{+}$} & & & $* * * *$ & & $\downarrow$ & \\
\hline & 9,35 (s) & nicotinamide $\mathrm{CH}$ & & & & \\
\hline & 9,15 (d) & nicotinamide $\mathrm{CH}$ & $* * * *$ & $* * * *$ & $\downarrow$ & \\
\hline & 8,84 (d) & nicotinamide $\mathrm{CH}$ & $* * * *$ & $* * * *$ & $\downarrow$ & \\
\hline & $8,43(s)$ & adenine $\mathrm{CH}$ & & & & ov \\
\hline & $8,20(\mathrm{dd}), 8,18(\mathrm{~s})$ & adenine $\mathrm{CH}$ & $* * * *$ & $* * * *$ & $\downarrow$ & \\
\hline & 6,10 (d) & ribose $\mathrm{CH}$ & $* * * *$ & $* * * *$ & $\downarrow$ & \\
\hline & 6,05 (d) & ribose $\mathrm{CH}$ & $* * * *$ & $* * * *$ & $\downarrow$ & \\
\hline & $4,55(m)$ & ribose $\mathrm{CH}$ & $* * * *$ & $* * * *$ & $\downarrow$ & ov \\
\hline & 4,52 (dd) & ribose $\mathrm{CH}$ & $* * * *$ & $* * * *$ & $\downarrow$ & ov \\
\hline & $4,50(m)$ & ribose $\mathrm{CH}$ & $* * * *$ & $* * * *$ & $\downarrow$ & ov \\
\hline & $4,43(m)$ & ribose $\mathrm{CH}$ & $* * *$ & $* * * *$ & $\downarrow$ & ov \\
\hline & $4,38(m)$ & ribose $\mathrm{CH}$ & $* * * *$ & $* * * *$ & $\downarrow$ & ov \\
\hline & $4,37(m)$ & ribose $\mathrm{CH}$ & & & & ov \\
\hline & $4,27(m)$ & $\mathrm{CH}_{2}$ & $* * * *$ & $* * * *$ & $\downarrow$ & ov \\
\hline & $4,25(m), 4,22(m)$ & $\mathrm{CH}_{2}$ & $* * * *$ & $* * * *$ & $\downarrow$ & ov \\
\hline \multirow[t]{7}{*}{ AMP } & & & $* * * *$ & $* * * *$ & $\downarrow$ & \\
\hline & $8,61(s)$ & adenine $\mathrm{CH}$ & $* * * *$ & $* * * *$ & $\downarrow$ & \\
\hline & $8,26(s)$ & adenine $\mathrm{CH}$ & & & & ov \\
\hline & $6,15(d)$ & ribose $\mathrm{CH}$ & $* * * *$ & $* * * *$ & $\downarrow$ & \\
\hline & $4,52(d d)$ & ribose $\mathrm{CH}$ & $* * * *$ & $* * * *$ & $\downarrow$ & ov \\
\hline & $4,38(m)$ & ribose $\mathrm{CH}$ & $* * * *$ & $* * * *$ & $\downarrow$ & ov \\
\hline & $4,02(m)$ & $\mathrm{CH}_{2}$ & $* * * *$ & $* * * *$ & $\downarrow$ & ov \\
\hline
\end{tabular}

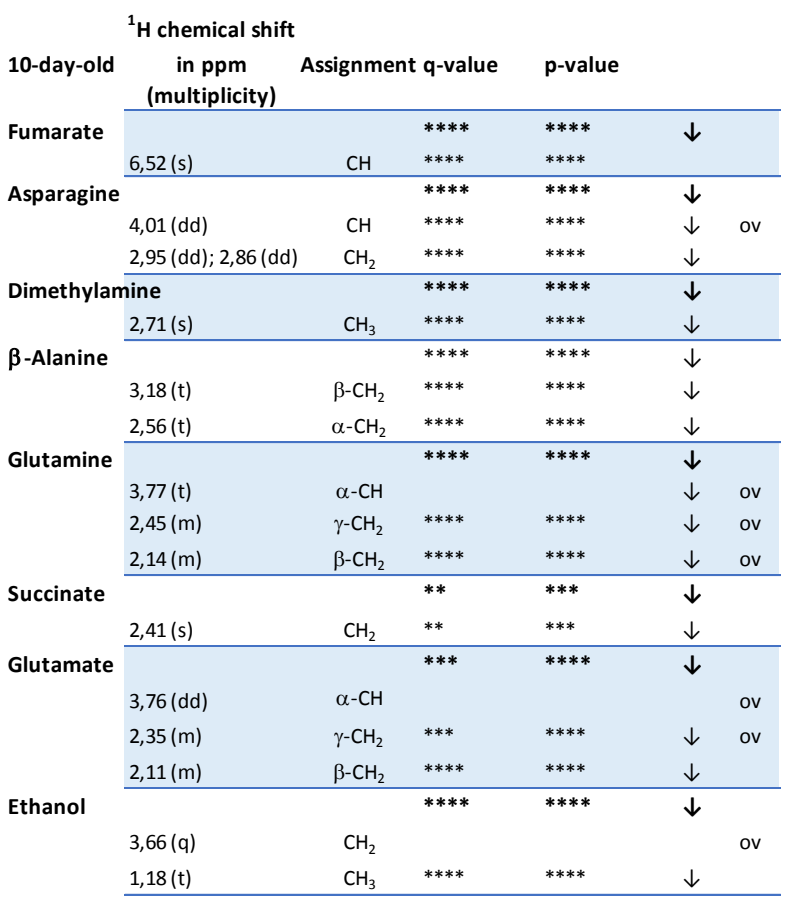

Table 1. Metabolites identified from the 79 common discriminant variables with VIP $>1$, for the 10-day-old flies. Downward arrows $(\downarrow)$ indicate that the ratio of metabolite was lower for HD flies than for controls. s- singlet, d- doublet, dd- doublet of doublet, t- triplet, m- multiplet. ${ }^{* *} 0.001<$ Value $<0.01 ;{ }^{* * *} 0.0001<$ Value $<0.001,{ }^{* * * *}$ Value $<0.0001$

\section{Symptomatic stage biomarkers}

The same procedure as for the 10-day-old flies was conducted for the 16-day-old flies (Figure 4). The discriminant variables (VIPs) $>1$ from OPLS-DA and showing confidence interval at the $95 \%$ level were retained: i) 156 variables were found between HD flies and 
the associated two controls, ii) 136 variables between HD flies and Gal4 controls and finally iii) 191 variables between HD flies and UAS controls. All the OPLS-DA analyses performed lead to a good or excellent separation of the groups. Correct R2X $(0.57 ; 0.71$ and 0.50 , respectively) and large $R 2 Y(0.95 ; 0.99$ and 0.98 , respectively) indicated high reproducibility and a good fitting of the model to the data. Q2Y parameters were calculated by cross validation and were close to $1(0.87 ; 0.89$ and 0.97 , respectively), which demonstrates the high predictivity of models. Furthermore, the discriminant variables produced by the three OPLS-DA analyses were compared to each other using a Venn diagram and the 46 common variables were retained.

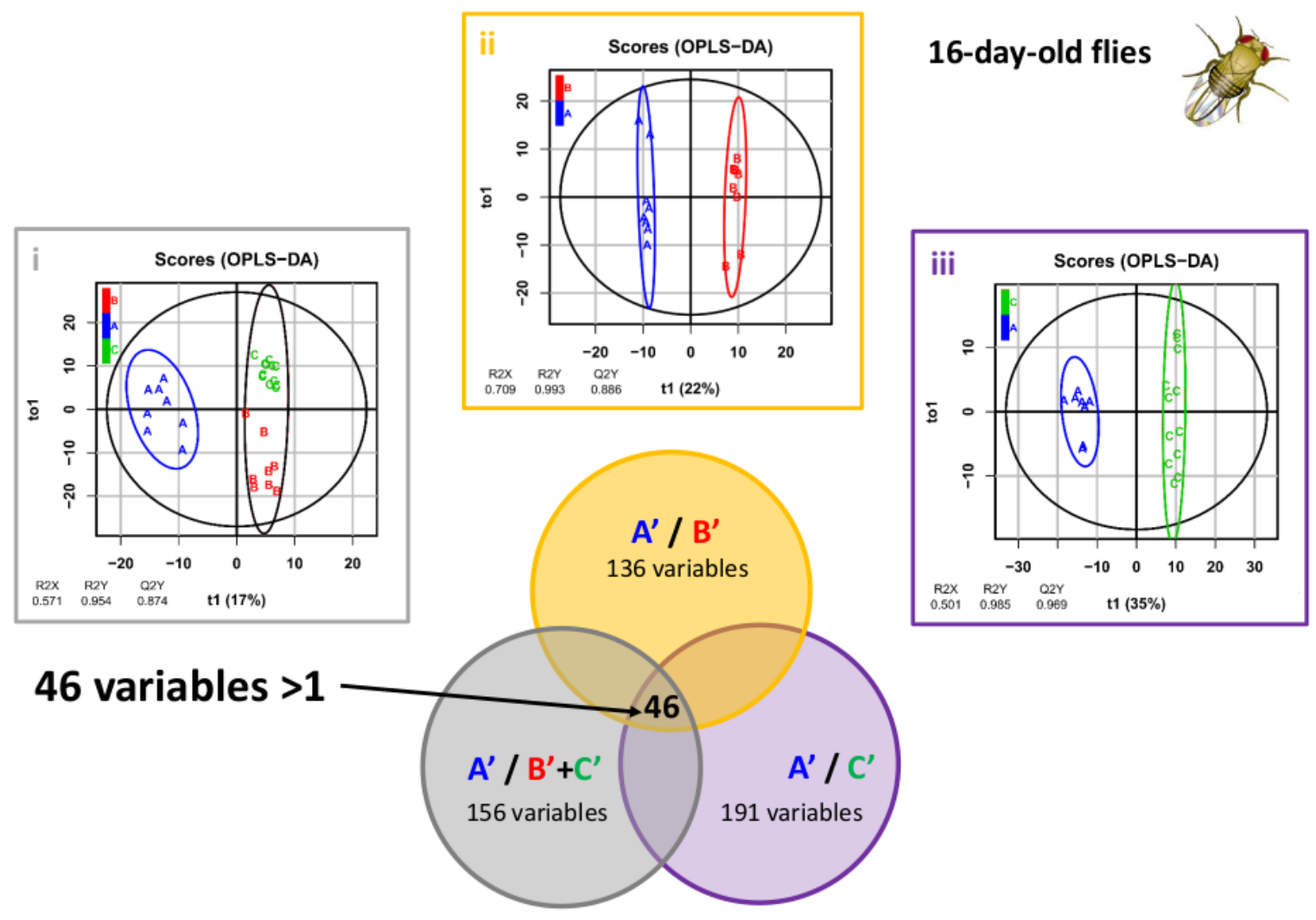


Figure 4. Discriminant variables at the symptomatic stage (16-day-old flies). OPLS-DA analyses performed between the three groups of samples of 16-day-old flies. (i): OPLSDA analysis for discrimination of HD flies and sum of Gal4 and UAS controls; (ii): OPLSDA analysis for discrimination of HD flies and Gal4 controls; (iii): OPLS-DA analysis for discrimination of HD flies and UAS controls. A Venn diagram shows the 46 variables common to the three sets of samples. A': HD flies (in blue), B': Gal4 controls (in red) and C': UAS controls (in green).

Only 6 metabolites were unambiguously identified from the 46 discriminant variables, and are presented in Table 2 (the VIP score of each of the discriminant metabolites is displayed in the Figure S3 as supporting information). Note that at this stage of the disease, four metabolic biomarkers have increased in HD flies, whereas two have decreased. 


\begin{tabular}{|c|c|c|c|c|c|c|}
\hline 16-day-old & $\begin{array}{c}{ }^{1} \mathrm{H} \text { chemical shift in ppm } \\
\text { (multiplicity) }\end{array}$ & Assignme & q-value & p-valu & & \\
\hline Phosphoch & oline & & $* * *$ & $* * * *$ & $\uparrow$ & \\
\hline & $4,17(m)$ & $\mathrm{CH}_{2}$ & $* * * *$ & $* * * *$ & $\uparrow$ & \\
\hline & $3,60(\mathrm{~m})$ & $\mathrm{CH}_{2}$ & $* * * *$ & $* * * *$ & $\uparrow$ & ov \\
\hline & $3,23(s)$ & $\mathrm{CH}_{3}$ & $* * *$ & $* * * *$ & $\uparrow$ & \\
\hline Ethanolami & & & & & & \\
\hline & $3,81(t)$ & $\mathrm{CH}_{2}$ & $* * * *$ & $* * * *$ & $\uparrow$ & \\
\hline & $3,12(t)$ & $\mathrm{CH}_{2}$ & $* * * *$ & $* * * *$ & $\uparrow$ & ov \\
\hline 2-Oxogluta & rate $(\alpha-K G)$ & & $* *$ & $* *$ & $\downarrow$ & \\
\hline & $3,00(t)$ & $\beta-\mathrm{CH}_{2}$ & $* *$ & $* *$ & $\downarrow$ & \\
\hline & $2,44(t)$ & $\alpha-\mathrm{CH}_{2}$ & $* *$ & $* *$ & $\downarrow$ & ov \\
\hline Succinate & & & $*$ & $*$ & $\uparrow$ & \\
\hline & $2,41(s)$ & $\mathrm{CH}_{2}$ & $*$ & $*$ & $\uparrow$ & \\
\hline Pyruvate & & & $* *$ & $* * *$ & $\downarrow$ & \\
\hline & $2,38(s)$ & $\mathrm{CH}_{3}$ & $* *$ & $* * *$ & $\downarrow$ & \\
\hline Acetate & & & $* *$ & $* *$ & $\uparrow$ & \\
\hline & $1,92(s)$ & $\mathrm{CH}_{3}$ & $* *$ & $* *$ & $\uparrow$ & \\
\hline
\end{tabular}

Table 2. Metabolites identified from the 46 common discriminant variables with VIP $>1$, for the 16-day-old flies. For metabolites with several peaks, the q-value is common to the different peaks. Downward arrows $(\downarrow)$ and upward arrows $(\uparrow)$ indicate that the proportion of metabolites was lower or, respectively, higher for HD flies than for controls. s- singlet, t- triplet, m- multiplet. ov- overlapped. ${ }^{*} 0.01<$ Value $<0.05 ;{ }^{* *} 0.001<$ Value $<0.01 ;{ }^{* * *}$ $0.0001<$ Value $<0.001$, Value $<0.0001$

\section{Analysis of biomarker change}

In order to follow the change of the identified metabolites with the progression of the disease, the comparison of 10-day-old and 16-day-old HD flies was carried out. The 
OPLS-DA analysis highlighted 177 discriminant variables (Figure 5), making it possible to identify 15 metabolites (Table 3). Note that all the metabolites previously identified (Tables 1 and 2) were discriminant between 10- and 16-day-old flies, with the exception of pyruvate. Taurine, which was not identified in the previous analysis, is now discriminant between 10- and 16-day-old HD flies.

To make sure that the change of biomarkers is well correlated with the progression of the disease and not with the age of flies, the same analysis was performed between 10- and 16-day-old control flies. Results are presented in Table 3. We observed that three metabolites (glutamate, acetate and ethanol) changed in the same way in diseased and control flies according to age.
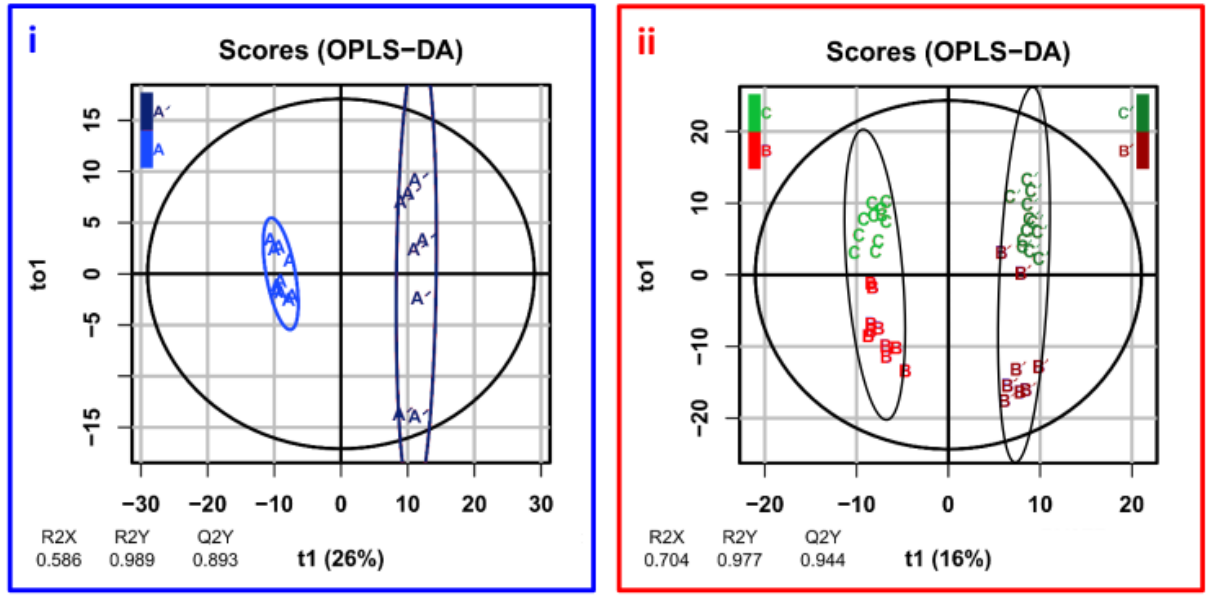

iii
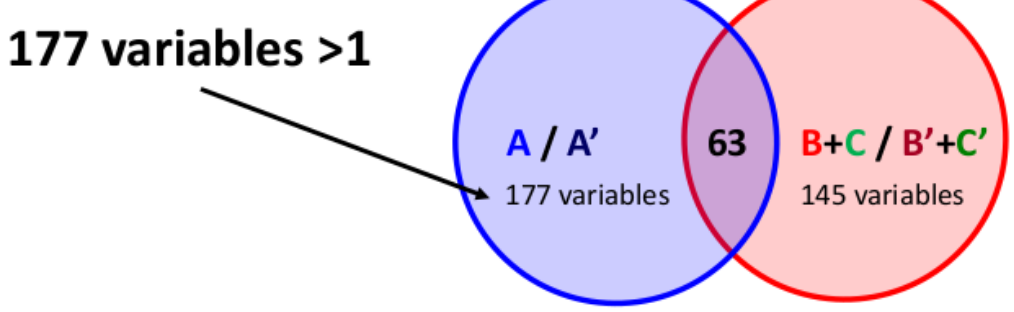
Figure 5. Discriminant variables over the course of the disease (10- and 16 day-old flies). OPLS-DA analyses performed between the samples of 10- and 16-day-old flies. (i): OPLSDA analysis for discrimination of 10-day-old HD flies and 16-day-old HD flies; (ii): OPLSDA analysis for discrimination of 10-day-old UAS and Gal4 controls and 16-day-old UAS and Gal4 controls; (iii): A Venn diagram shows the 177 variables characteristic of the evolution of the disease. The 63 common variables are characteristic of the progression of the disease and of the age. A and A': HD flies at 10- and 16-day old, respectively (in light and dark blue), B and B': Gal4 controls at 10- and 16-day old, respectively (in light and dark red) and C and C': UAS controls at 10- and 16-day old, respectively (in light and dark green).

10/16-day-old HD flies

q-value $p$-value evolving q-value $p$-value evolving with HD with age

\begin{tabular}{|c|c|c|c|c|c|c|}
\hline $\mathrm{NAD}^{+}$ & $*$ & $*$ & $\uparrow$ & & & \\
\hline AMP & $*$ & $*$ & $\uparrow$ & $* * *$ & $* * *$ & $\downarrow$ \\
\hline Fumarate & $*$ & $*$ & $\uparrow$ & & & \\
\hline Taurine & $* * * *$ & $* * * *$ & $\uparrow$ & & & \\
\hline Phosphocholine & $* *$ & $* * *$ & $\uparrow$ & & & \\
\hline Ethanolamine & $* *$ & $* *$ & $\uparrow$ & & & \\
\hline 2-Oxoglutarate & $* *$ & $* * *$ & $\downarrow$ & & & \\
\hline Asparagine & $*$ & $* *$ & $\uparrow$ & $* * * *$ & $* * * *$ & $\downarrow$ \\
\hline Dimethylamine & $* *$ & $* * *$ & $\uparrow$ & & & \\
\hline$\beta$-Alanine & $* *$ & $* *$ & $\uparrow$ & & & \\
\hline Glutamine & $*$ & $*$ & $\uparrow$ & $* * *$ & $* * *$ & $\downarrow$ \\
\hline Succinate & $* *$ & $* *$ & $\uparrow$ & & & \\
\hline Glutamate & $*$ & $*$ & $\downarrow$ & $* * * *$ & $* * * *$ & $\downarrow$ \\
\hline Acetate & $* * *$ & $* * * *$ & $\uparrow$ & $* *$ & $* *$ & $\uparrow$ \\
\hline Ethanol & $* * * *$ & $* * * *$ & $\downarrow$ & $* * * *$ & $* * * *$ & $\downarrow$ \\
\hline
\end{tabular}

Table 3. Metabolites changing with HD disease stage and/or with age. Downward arrows

$(\downarrow)$ and upward arrows $(\uparrow)$ indicate that the proportion of metabolites was lower or, 
respectively, higher for 10 -day-old than for 16 -day-old HD flies. ${ }^{*} 0.01<$ Value $<0.05$; ${ }^{*}$ $0.001<$ Value $<0.01 ;{ }^{* * *} 0.0001<$ Value $<0.001 ;{ }^{* * \star *}$ Value $<0.0001$

\section{Discrimination performance of biomarkers}

We have performed ROC analysis to evaluate the predictive value of the discriminant metabolites. ROC curves were constructed with different combination (2 to 46 variables). The results of multi-ROC analyses showed that the models with 10 or more variables have an area under the curve (AUC) greater than 95\% (see Figure S4). The AUC value close to 1 shows high sensitivity and specificity of the model. Then, a set of 15 discriminant metabolites were manually selected based on their LASSO frequencies and of their mean importance measures (phosphocholine, glutamine, pyruvate, taurine, $\beta$-alanine, succinate, acetate, 2-oxoglutarate, ethanol, ethanolamine, $\mathrm{NAD}^{+}, \mathrm{AMP}$, fumarate, glutamate and dimethylamide). The significance of this biomarker model was evaluated using ROC curve and logistic regression (Figure S5). Then different sets of samples were tested to see if the set of the 15 variables was able to sort the HD samples from the controls. The predicted class probabilities for each sample showed a good classification accuracy where 29 out of 30 samples were correctly classified (example on Figure S6).

\section{DISCUSSION}


In this study, a transgenic model of HD in Drosophila melanogaster has been used to identify metabolic biomarkers at presymptomatic (10-day-old flies) and symptomatic (16day-old flies) stages of the disease. Our study has been performed on the whole body of the flies because in this model the mutant $\mathrm{Htt}$ has been expressed in all fly neurons, which are present in the head as components of the brain, but also in other parts of the fly body, such as the ventral nerve cord in the thorax or the enteric nervous system in the abdomen. A complete analysis of HD-associate defects in our model therefore required to study metabolites in the entire fly. Moreover, brain activity and state are known to influence the physiology of the whole organism, both in health and disease conditions. The discriminant metabolites between the disease carrier flies and their controls were identified by ${ }^{1} \mathrm{H}-\mathrm{NMR}$ and OPLS-DA multivariate analyses. This allowed a better understanding of the metabolic impairments associated with the disease and to follow the metabolite disturbance over its progression.

The three statistical analyses reported here enabled us to: i) identify 10 biomarkers of the presymptomatic stage; ii) identify 6 biomarkers of the symptomatic stage and finally, iii) monitor the change of these biomarkers during HD-like pathogenesis. It is worth mentioning that some metabolites could not be unambiguously identified from discriminant variables. Therefore, the final lists of metabolites only report the compounds that we could identified with certainty. Moreover, the regions corresponding to residual lipid peaks in NMR spectra were removed from the matrix before the statistical analyses, in order not to affect the results. As a consequence, the lactate peaks, at 1.33 and $1.35 \mathrm{ppm}$, could not be considered in our work although lactate is a known HD biomarker which has been highlighted in several previous studies. ${ }^{17,24,50}$ 
The discriminating performance of these metabolites was tested on the whole samples by an exploratory analysis using multivariate ROC curves. A minimum of ten metabolites is required to have a good discriminant ability. A set of 15 metabolites allows to class between HD and control samples with a good accuracy and to predict them.

The metabolites identified in our study can be classified in three groups: i) the first group includes the metabolites directly involved in energy metabolism (fumarate, succinate, 2oxoglutarate (or $\alpha$-ketoglutarate), pyruvate, acetate, $\mathrm{NAD}^{+}$and $\mathrm{AMP}$ ), ii) the second group corresponds to amino acids and derivatives (glutamate, glutamine, asparagine, $\beta$-alanine and taurine), and iii) the third group corresponds to miscellaneous metabolites (dimethylamine, acetate, phosphocholine, ethanol and ethanolamine). Most of these discriminant metabolites have been reported in the literature as biomarkers of $\mathrm{HD}$, in particular glutamate, ${ }^{13,14,51,52}$ glutamine, ${ }^{12,13,17,20,24,50,52,53}$ phosphocholine, ${ }^{13,15,16,23}$ acetate, ${ }^{50,53}$ succinate $^{17,24,53}$ and pyruvate. ${ }^{24,54,55}$ Other metabolites, such as leucine, isoleucine, $\quad$ valine, ${ }^{23,56,57}$ myo-inositol, ${ }^{11,58,59} \mathrm{~N}$-acetyl-aspartate $\quad(\mathrm{NAA}),{ }^{14,58,60} \gamma$ aminobutyric acid (GABA) ${ }^{10,12,22}$ were quite often pointed out, but they did not appear as discriminant in our analyses. The closest report to our study is the recent work of Singh and collaborators ${ }^{24}$ on a Drosophila model of HD displaying retinal deformations. Among the metabolites they identified by NMR analysis performed on methanolic extracts of heads, four are common to ours: $\mathrm{NAD}^{+}$, pyruvate, succinate and glutamine. These authors used the GMR-Gal4 driver, which selectively expresses in the fly compound eyes, explaining why the analysis was focused on heads, unlike our model in which mutant $\mathrm{Htt}$ is expressed in all neurons present over the entire body. Our analysis was carried out, 
therefore, on a larger diversity of neuronal subtypes than that used in Singh's study. The eye photoreceptors are highly specialized cells that are different from all other neurons, so one can expect that the results obtained in the retina will not be identical to those obtained in brain or other tissues. However, it is interesting to note the similarities between our results and those of Singh et al., particularly regarding energetic pathways.

Brain energy supply is well known to be dysfunctional in HD. ${ }^{61,62}$ Numerous evidence suggests a dysfunction of mitochondria in HD, and more specifically of the electron transport chain. However, other energy generating pathways are also implicated. In particular, the tricarboxylic acid (TCA) cycle is disrupted, ${ }^{17,63}$ and compensatory pathways are used to fuel the TCA cycle, such as fatty acid oxidation or glutamate oxidation for example. It has been shown that increasing glucose transport in neurons significantly enhanced Drosophila survival in the Httex1p Q93 model. ${ }^{48}$ The same authors observed that overexpression of glucose-6-phosphate dehydrogenase (G6PD), the key enzyme in the pentose phosphate (PPP) pathway, also markedly extended the lifespan of HD flies. Our results highlight metabolites involved in such bioenergetic pathways: fumarate, succinate and 2-oxoglutarate, which are intermediates of the TCA cycle, and pyruvate, which is the end product of glycolysis. Acetate is also involved in energy metabolism as it may derived from fatty acid oxidation, a pathway used when carbohydrates are low. Polyzos et al. showed in a mouse model of $\mathrm{HD}(\mathrm{HdhQ}(150 / 150))$ that the level of glucose was lower in the striatum of HD mice, and that astrocytes reprogramed their metabolism to use fatty acids as a fuel. ${ }^{64} \mathrm{NAD}^{+}$and $\mathrm{NADP}^{+}$are coenzymes in enzymatic oxidationreduction (redox) reactions such as glycolysis and the TCA cycle. They are also involved 
in the electron transport chain. A decrease in NAD+ was already noted in two studies with two different animal models of HD : Drosophila ${ }^{24}$ and the mouse.$^{65}$

Among the amino acids identified at presymptomatic stage, glutamate and glutamine are non-essential amino acids, which are involved in brain functions. In neurons, glutamate acts as an excitatory neurotransmitter. In astrocytes, it is used to produce glutamine, which is transported into neurons and then converted into glutamate. However, glutamate may also participate to fuel the TCA cycle by generating 2-oxoglutarate. At 10 days, HD flies have a lower level of glutamate and glutamine than controls, which may suggest that these two amino acids are preferentially used to produce energy. We also noticed a decrease in asparagine at presymptomatic stage. This was already reported in the metabolic profiling of presymptomatic HD in sheep ${ }^{23}$ and in the plasma of HD patients. ${ }^{66}$ Like glutamate, asparagine can also participates in energy metabolism as an intermediate of oxaloacetate.

Finally, other metabolites such as phosphocholine and ethanolamine were found to increase at symptomatic stage in our model. They are precursors of phosphatidylcholine and phosphatidylethanolamine, which are major components of cellular and mitochondrial membranes and more specifically of the neuronal membranes. The increase in phosphocholine and ethanolamine observed in this study likely reflects therefore an altered turnover of membranes resulting from neurodegeneration. Alterations in phosphocholine levels have previously been reported in the blood of HD patients ${ }^{15}$ and in various mouse models. ${ }^{13,67,68}$ 
$\mathrm{HD}$ is a progressive disease that gets worse with age and it is tempting to think that metabolic alterations will also worsen with age. However, Dubinsky ${ }^{63}$ suggested that the compensation phenomena that arise in HD evolve in the course of the disease. In this study, we have highlighted the discriminating metabolites in presymptomatic and symptomatic flies. Comparative analysis between the 10-day-old HD flies and 16-day-old HD flies identifies 15 discriminants metabolites. Among them, three (glutamate, acetate and ethanol) were also discriminant between 10-day-old and 16-day-old control flies suggesting that the variation in the rate of these metabolites is more a consequence of age rather than of the course of the disease. With the exception of taurine, these metabolites are those identified in 10-day-old and 16-day-old HD flies. Most of these metabolites were discriminant only in 10-day-old HD flies or only in 16-day-old HD flies when comparing to their controls. For example, fumarate has a lower level when compared with controls in 10-day-old HD flies, but was not discriminant when the 16-dayold HD flies were compared to their controls. These results suggest that discriminating metabolites at 10 days returned to a normal level at 16 days and that new discriminating metabolites appeared at this stage. Regarding succinate, its level changes in the opposite direction compared to the controls between these two stages, decreasing in 10-day-old HD flies, but increasing in 16-day-old HD flies. It is interesting to note that taurine is not discriminating when comparing 10-day-old and 16-day-old HD flies with their controls, but emerges as a discriminating metabolite when comparing 10-day-old and 16-day old HD flies. The discriminating metabolites retained in the results are those common from the three comparison pairs HD flies / Gal4 controls, HD flies / UAS controls and HD flies / sum of controls, as indicated. In this case taurine was not discriminant, but when comparing 10-day-old and 16-day-old HD flies only with the sum of the controls or only with the Gal4 
control taurine was discriminant, its level being lower in 10-day-old HD flies and higher in 16-day-old HD flies. If the taurine level changes in an opposite direction in 10-day-old and 16-day-old HD flies, taurine can become a discriminating metabolite between these two stages of the disease.

Taurine is a sulfur-containing amino-acid displaying multiple functions. ${ }^{22,56,59} \mathrm{It}$ is involved in brain development, neuromodulation, osmoregulation, stabilization of membranes, inflammation, neuroprotection and it has also an antioxidant function. ${ }^{69}$ Recently, it has been shown that taurine has a protective effect in models of neurodegenerative disorders and in particular in a rat HD model. ${ }^{70,71}$ The change in taurine level during the progression of the disease in our Drosophila model, could reflect this role in neuroprotection.

As a whole, our results describe that some metabolites decrease at early stage and increase at a later stage, demonstrating that the impairments in metabolite pathways change over the course of the disease. Such observations have already been noted in the literature. ${ }^{63,64} \mathrm{~A}$ majority of the metabolites identified in this study are related to energy metabolism, they are intermediates of the TCA cycle or intermediates of compensatory energy mediating pathways such as fatty acid oxidation or oxidative glutamate pathway. During the progression of the disease, the cells adapt their metabolism to compensate the deficit in energy, but adopt different compensatory pathways based on accumulated metabolic and transcriptional alterations. The different energy supply pathways are tightly regulated and interconnected. For example, AMP activates several enzymes of the TCA cycle (pyruvate dehydrogenase, citrate synthase and isocitrate dehydrogenase) and the ratio $\mathrm{NAD}^{+}$/ $\mathrm{NADH}$ influences the pyruvate / lactate ratio. ${ }^{63}$ Other studies have reported 
different expression rates of enzymes involved in energy biosynthesis pathways. For example, Zabel et al. ${ }^{72}$ have shown the up-regulation of enzymes involved in glycolysis and gluconeogenesis in 2 weeks R6/2 mice. Using the same model, Perluigi et al. ${ }^{73}$ have demonstrated an increasing expression level of dihydrolipoamide S-succinyl-transferase and aspartate aminotransferase over the course of disease (10-week-old mice) and a decrease in pyruvate dehydrogenase expression level in 10-week-old HD transgenic mice compared with young (4-week-old) mice. In addition, expression of mhtt may affect transcriptional activity and may result in alteration in expression of proteins involved in energy metabolism as demonstrated by Naia et al. ${ }^{74}$ who found in striatal $H d h Q^{111 / 111}$ cells an increase of pyruvate dehydrogenase kinase expression leading to a decrease of pyruvate dehydrogenase activity.

\section{CONCLUSION}

In HD, changes in metabolite levels precede structural brain alterations. Therefore, the study of molecular biomarkers at a presymptomatic stage is essential to understand better the pathogenesis and to find new therapeutic targets. Our work identifies 16 discriminatory metabolites at presymptomatic and symptomatic stages of HD modeled in Drosophila melanogaster. These metabolites confirm dysfunctions in energy production leading to mitochondrial dysfunction and a disruption of glycolysis, TCA and glutamate-glutamine cycles. Our results suggest that a set of 15 metabolites characteristic of both stages of the disease could be used to distinguish HD flies from controls, indicating that they have a predictive value. As defined here on a Drosophila model, among this 15 metabolites, nine metabolites, namely $\mathrm{NAD}^{+}$, fumarate, taurine, ethanolamine, dimethylamine, $\beta$ - 
alanine, succinate, phosphocholine and 2-oxoglutarate, shown to be independent of age, may be considered first to follow the progression of HD in flies. They could be considered as potential candidates to be tested in other HD models and in human patients.

\section{ACKNOWLEDGMENTS}

The authors acknowledge the CNRS and the "Centre Val de Loire" region for their financial support. 


\section{SUPPORTING INFORMATION:}

Figure $\mathrm{S} 1-{ }^{13} \mathrm{C}$-HSQC spectra of 16 -day-old HD flies.

Figure S2 - VIP score of the metabolites for the 10-day-old flies extracted from the OPLS-DA table.

Figure S3 - VIP score of the metabolites for the 16-day-old flies extracted from the OPLS-DA table.

Figure S4 - Plot of ROC curves for several biomarker models based on their average performance.

Figure S5 - Plot of the ROC curve for the 15 biomarker model

Figure S6. Predicted class probability plots (average of the cross-validation) for each of the 30 samples using the base classifier (based with 15 metabolite variables). 


\section{REFERENCES}

(1) Macdonald, M. E.; Ambrose, C. M.; Duyao, M. P.; Myers, R. H.; Lin, C.; Srinidhi, L.; Barnes, G.; Taylor, S. A.; James, M.; Groot, N. et al. A novel gene containing a trinucleotide repeat that is expanded and unstable on Huntington's disease chromosones. Cell 1993, 72 (6), 971-983.

(2) Andrew, S. E.; Goldberg, Y. P.; Kremer, B.; Telenius, H.; Theilmann, J.; Adam, S.;

Starr, E.; Squitieri, F.; Lin, B. Y.; Kalchman, M. A. et al. The relationship between trinucleotide (CAG) repeat length and clinical-features of Huntingtons-Disease. Nature Genetics 1993, 4 (4), 398-403.

(3) Saudou, F.; Humbert, S. The Biology of Huntingtin. Neuron 2016, 89 (5), 910-926.

(4) Carroll, J. B.; Bates, G. P.; Steffan, J.; Saft, C.; Tabrizi, S. J. Treating the whole body in Huntington's disease. Lancet Neurology 2015, 14 (11), 1135-1142.

(5) Bates, G. P.; Dorsey, R.; Gusella, J. F.; Hayden, M. R.; Kay, C.; Leavitt, B. R.; Nance, M.; Ross, C. A.; Scahill, R. I.; Wetzel, R. et al. Huntington disease. Nature Reviews Disease Primers 2015, 1, 15005.

(6) Labbadia, J.; Morimoto, R. I. Huntington's disease: underlying molecular mechanisms and emerging concepts. Trends in Biochemical Sciences 2013, 38 (8), 378-385.

(7) McColgan, P.; Tabrizi, S. J. Huntington's disease: a clinical review. European Journal of Neurology 2018, 25 (1), 24-34.

(8) Caboche, J.; Vanhoutte, P.; Boussicault, L.; Roze, E.; Betuing, S. In Handbook of Behavioral Neuroscience; Steiner, H.;Tseng, K. Y., Eds.; Elsevier, 2016; Vol. 24. 
(9) Illarioshkin, S. N.; Klyushnikov, S. A.; Vigont, V. A.; Seliverstov, Y. A.;

Kaznacheyeva, E. V. Molecular Pathogenesis in Huntington's Disease.

Biochemistry-Moscow 2018, 83 (9), 1030-1039.

(10) Dumas, M. E.; Davidovic, L. Metabolic Profiling and Phenotyping of Central Nervous System Diseases: Metabolites Bring Insights into Brain Dysfunctions. Journal of Neuroimmune Pharmacology 2015, 10 (3), 402-424.

(11) Graham, S. F.; Kumar, P. K.; Bjorndahl, T.; Han, B.; Yilmaz, A.; Sherman, E.;

Bahado-Singh, R. O.; Wishart, D.; Mann, D.; Green, B. D. Metabolic signatures of Huntington's disease (HD): $\mathrm{H}-1$ NMR analysis of the polar metabolome in postmortem human brain. Biochimica Et Biophysica Acta-Molecular Basis of Disease 2016, $1862(9)$, 1675-1684.

(12) Patassini, S.; Begley, P.; Xu, J. S.; Church, S. J.; Reid, S. J.; Kim, E. H.; Curtis, M. A.; Dragunow, M.; Waldvogel, H. J.; Snell, R. G. et al. Metabolite mapping reveals severe widespread perturbation of multiple metabolic processes in Huntington's disease human brain. Biochimica Et Biophysica Acta-Molecular Basis of Disease 2016, $1862(9), 1650-1662$.

(13) Pepin, J.; Francelle, L.; Carrillo-de Sauvage, M. A.; de Longprez, L.; Gipchtein, P.; Cambon, K.; Valette, J.; Brouillet, E.; Flament, J. In vivo imaging of brain glutamate defects in a knock-in mouse model of Huntington's disease. Neuroimage 2016, 139, 53-64.

(14) Unschuld, P. G.; Edden, R. A. E.; Carass, A.; Liu, X. Y.; Shanahan, M.; Wang, X.; Oishi, K.; Brandt, J.; Bassett, S. S.; Redgrave, G. W. et al. Brain metabolite alterations and cognitive dysfunction in early Huntington's disease. Movement Disorders 2012, 27 (7), 895-902. 
(15) Mastrokolias, A.; Pool, R.; Mina, E.; Hettne, K. M.; van Duijn, E.; van der Mast, R. C.; van Ommen, G.; t Hoen, P. A. C.; Prehn, C.; Adamski, J. et al. Integration of targeted metabolomics and transcriptomics identifies deregulation of phosphatidylcholine metabolism in Huntington's disease peripheral blood samples. Metabolomics 2016, 12 (8), 137.

(16) Cheng, M.-L.; Chang, K.-H.; Wu, Y.-R.; Chen, C.-M. Metabolic disturbances in plasma as biomarkers for Huntington's disease. Journal of Nutritional Biochemistry 2016, 31, 38-44.

(17) Verwaest, K. A.; Vu, T. N.; Laukens, K.; Clemens, L. E.; Nguyen, H. P.; Van Gasse, B.; Martins, J. C.; Van der Linden, A.; Dommisse, R. H-1 NMR based metabolomics of CSF and blood serum: A metabolic profile for a transgenic rat model of Huntington disease. Biochimica Et Biophysica Acta-Molecular Basis of Disease 2011, 1812 (11), 1371-1379.

(18) Pont, L.; Benavente, F.; Jaumot, J.; Tauler, R.; Alberch, J.; Gines, S.; Barbosa, J.; Sanz-Nebot, V. Metabolic profiling for the identification of Huntington biomarkers by on-line solid-phase extraction capillary electrophoresis mass spectrometry combined with advanced data analysis tools. Electrophoresis 2016, 37 (5-6), 795808.

(19) Ismailoglu, I.; Chen, Q.; Popowski, M.; Yang, L.; Gross, S. S.; Brivanlou, A. H. Huntingtin protein is essential for mitochondrial metabolism, bioenergetics and structure in murine embryonic stem cells. Developmental Biology 2014, 391 (2), 230-240.

(20) Zacharoff, L.; Tkac, I.; Song, Q. F.; Tang, C. N.; Bolan, P. J.; Mangia, S.; Henry, P. G.; Li, T. B.; Dubinsky, J. M. Cortical metabolites as biomarkers in the R6/2 model 
of Huntington's disease. Journal of Cerebral Blood Flow and Metabolism 2012, 32 (3), 502-514.

(21) Chang, K. L.; New, L. S.; Mal, M.; Goh, C. W.; Aw, C. C.; Browne, E. R.; Chan, E. C. Y. Metabolic Profiling of 3-Nitropropionic Acid Early-Stage Huntington's Disease Rat Model Using Gas Chromatography Time-of-Flight Mass Spectrometry. Journal of Proteome Research 2011, 10 (4), 2079-2087.

(22) Tsang, T. M.; Haselden, J. N.; Holmes, E. Metabonomic Characterization of the 3Nitropropionic Acid Rat Model of Huntington's Disease. Neurochemical Research 2009, 34 (7), 1261-1271.

(23) Skene, D. J.; Middleton, B.; Fraser, C. K.; Pennings, J. L. A.; Kuchel, T. R.; Rudiger, S. R.; Bawden, C. S.; Morton, A. J. Metabolic profiling of presymptomatic Huntington's disease sheep reveals novel biomarkers. Scientific Reports 2017, 7. (24) Singh, V.; Sharma, R. K.; Athilingam, T.; Sinha, P.; Sinha, N.; Thakur, A. K. NMR Spectroscopy-based Metabolomics of Drosophila Model of Huntington's Disease Suggests Altered Cell Energetics. Journal of Proteome Research 2017, 16 (10), 3863-3872.

(25) Rosas-Arellano, A.; Estrada-Mondragon, A.; Pina, R.; Mantellero, C. A.; Castro, M. A. The Tiny Drosophila Melanogaster for the Biggest Answers in Huntington's Disease. International Journal of Molecular Sciences 2018, 19 (8), 2398.

(26) Marsh, J. L.; Thompson, L. M. Drosophila in the study of neurodegenerative disease. Neuron 2006, 52 (1), 169-178.

(27) McGurk, L.; Berson, A.; Bonini, N. M. Drosophila as an In Vivo Model for Human Neurodegenerative Disease. Genetics 2015, 201 (2), 377-402. 
(28) Lewis, E. A.; Smith, G. A. Using Drosophila models of Huntington's disease as a translatable tool. Journal of Neuroscience Methods 2016, 265, 89-98.

(29) Lin, D. M.; Goodman, C. S. Ectopic and increased expression of fasciclin-II alters motoneuron growth cone guidance. Neuron 1994, 13 (3), 507-523.

(30) Steffan, J. S.; Bodai, L.; Pallos, J.; Poelman, M.; McCampbell, A.; Apostol, B. L.; Kazantsev, A.; Schmidt, E.; Zhu, Y. Z.; Greenwald, M. et al. Histone deacetylase inhibitors arrest polyglutamine-dependent neurodegeneration in Drosophila. Nature 2001, 413 (6857), 739-743.

(31) Ott, S.; Vishnivetskaya, A.; Malmendal, A.; Crowther, D. C. Metabolic changes may precede proteostatic dysfunction in a Drosophila model of amyloid beta peptide toxicity. Neurobiology of Aging 2016, 41, 39-52.

(32) Sarup, P.; Pedersen, S. M. M.; Nielsen, N. C.; Malmendal, A.; Loeschcke, V. The Metabolic Profile of Long-Lived Drosophila melanogaster. Plos One 2012, 7 (10), e47461.

(33) Zhang, Z.-M.; Chen, S.; Liang, Y.-Z. Baseline correction using adaptive iteratively reweighted penalized least squares. Analyst 2010, 135 (5), 1138-1146.

(34) Bloemberg, T. G.; Gerretzen, J.; Wouters, H. J. P.; Gloerich, J.; van Dael, M.; Wessels, H. J. C. T.; van den Heuvel, L. P.; Eilers, P. H. C.; Buydens, L. M. C.; Wehrens, R. Improved parametric time warping for proteomics. Chemometrics and Intelligent Laboratory Systems 2010, 104 (1), 65-74.

(35) Wehrens, R. Chemometrics with R : Multivariate Data Analysis in the Natural Sciences and Life Sciences; Springer-Verlag Berlin Heidelberg GmbH \& Co. K, 2011, 20-31. 
(36) Jacob, D.; Deborde, C.; Lefebvre, M.; Maucourt, M.; Moing, A. NMRProcFlow: a graphical and interactive tool dedicated to 1D spectra processing for NMR- based metabolomics. Metabolomics 2017, 13 (4), 36.

(37) De Meyer, T.; Sinnaeve, D.; Van Gasse, B.; Tsiporkova, E.; Rietzschel, E. R.; De Buyzere, M. L.; Gillebert, T. C.; Bekaert, S.; Martins, J. C.; Van Criekinge, W. NMR-based characterization of metabolic alterations in hypertension using an adaptive, intelligent binning algorithm. Analytical Chemistry 2008, 80 (10), 37833790.

(38) Giacomoni, F.; Le Corguille, G.; Monsoor, M.; Landi, M.; Pericard, P.; Petera, M.; Duperier, C.; Tremblay-Franco, M.; Martin, J.-F.; Jacob, D. et al. Workflow4Metabolomics: a collaborative research infrastructure for computational metabolomics. Bioinformatics 2015, 31 (9), 1493-1495.

(39) Trygg, J.; Holmes, E.; Lundstedt, T. Chemometrics in metabonomics. Journal of Proteome Research 2007, 6 (2), 469-479.

(40) Colquhoun, D. An investigation of the false discovery rate and the misinterpretation of p-values. Royal Society Open Science 2014, 1 (3), 140216.

(41) Wishart, D. S.; Feunang, Y. D.; Marcu, A.; Guo, A. C.; Liang, K.; Vazquez-Fresno, R.; Sajed, T.; Johnson, D.; Li, C.; Karu, N. et al. HMDB 4.0: the human metabolome database for 2018. Nucleic Acids Research 2018, 46 (D1), D608D617.

(42) Ulrich, E. L.; Akutsu, H.; Doreleijers, J. F.; Harano, Y.; loannidis, Y. E.; Lin, J.; Livny, M.; Mading, S.; Maziuk, D.; Miller, Z. et al. BioMagResBank. Nucleic Acids Research 2008, 36, D402-D408. 
(43) Xia, J.; Sinelnikov, I. V.; Han, B.; Wishart, D. S. MetaboAnalyst 3.0-making metabolomics more meaningful. Nucleic Acids Research 2015, 43 (W1), W251W257.

(44) Lievens, J. C.; Rival, T.; Iche, M.; Chneiweiss, H.; Birman, S. Expanded polyglutamine peptides disrupt EGF receptor signaling and glutamate transporter expression in Drosophila. Human Molecular Genetics 2005, 14 (5), 713-724.

(45) Lievens, J.-C.; Iche, M.; Laval, M.; Faivre-Sarrailh, C.; Birman, S. AKT-sensitive or insensitive pathways of toxicity in glial cells and neurons in Drosophila models of Huntington's disease. Human Molecular Genetics 2008, 17 (6), 882-894.

(46) Pallos, J.; Bodai, L.; Lukacsovich, T.; Purcell, J. M.; Steffan, J. S.; Thompson, L. M.; Marsh, J. L. Inhibition of specific HDACs and sirtuins suppresses pathogenesis in a Drosophila model of Huntington's disease. Human Molecular Genetics 2008, 17 (23), 3767-3775.

(47) Zhang, S.; Feany, M. B.; Saraswati, S.; Littleton, J. T.; Perrimon, N. Inactivation of Drosophila Huntingtin affects long-term adult functioning and the pathogenesis of a Huntington's disease model. Disease Models \& Mechanisms 2009, 2 (5-6), 247266.

(48) Besson, M. T.; Alegria, K.; Garrido-Gerter, P.; Barros, L. F.; Lievens, J.-C. Enhanced Neuronal Glucose Transporter Expression Reveals Metabolic Choice in a HD Drosophila Model. Plos One 2015, 10 (3), e0118765.

(49) Besson, M.-T.; Dupont, P.; Fridell, Y.-W. C.; Lievens, J.-C. Increased energy metabolism rescues glia-induced pathology in a Drosophila model of Huntington's disease. Human Molecular Genetics 2010, 19 (17), 3372-3382. 
(50) Tsang, T. A.; Woodman, B.; McLoughlin, G. A.; Griffin, J. L.; Tabrizi, S. J.; Bates, G. P.; Holmes, E. Metabolic characterization of the R6/2 transgenic mouse model of Huntington's disease by high-resolution MAS (1)H NMR spectroscopy. Journal of Proteome Research 2006, 5 (3), 483-492.

(51) Graham, S. F.; Kumar, P.; Bahado-Singh, R. O.; Robinson, A.; Mann, D.; Green, B. D. Novel Metabolite Biomarkers of Huntington's Disease As Detected by HighResolution Mass Spectrometry. Journal of Proteome Research 2016, 15 (5), $1592-1601$.

(52) Behrens, P. F.; Franz, P.; Woodman, B.; Lindenberg, K. S.; Landwehrmeyer, G. B. Impaired glutamate transport and glutamate-glutamine cycling: downstream effects of the Huntington mutation. Brain 2002, 125, 1908-1922.

(53) Joyner, P. M.; Matheke, R. M.; Smith, L. M.; Cichewicz, R. H. Probing the Metabolic Aberrations Underlying Mutant Huntingtin Toxicity in Yeast and Assessing Their Degree of Preservation in Humans and Mice. Journal of Proteome Research 2010, $9(1), 404-412$.

(54) Naia, L.; Ribeiro, M.; Rodrigues, J.; Duarte, A. I.; Lopes, C.; Rosenstock, T. R.; Hayden, M. R.; Rego, A. C. Insulin and IGF-1 regularize energy metabolites in neural cells expressing full-length mutant huntingtin. Neuropeptides 2016, 58, 7381.

(55) Papsdorf, K.; Kaiser, C. J. O.; Drazic, A.; Grotzinger, S. W.; Haessner, C.; Eisenreich, W.; Richter, K. Polyglutamine toxicity in yeast induces metabolic alterations and mitochondrial defects. BMC Genomics 2015, 16 (1), 662. 
(56) Cheng, M. L.; Chang, K. H.; Wu, Y. R.; Chen, C. M. Metabolic disturbances in plasma as biomarkers for Huntington's disease. Journal of Nutritional Biochemistry 2016, 31, 38-44.

(57) Mochel, F.; Charles, P.; Seguin, F.; Barritault, J.; Coussieu, C.; Perin, L.; Le Bouc, Y.; Gervais, C.; Carcelain, G.; Vassault, A. et al. Early Energy Deficit in Huntington Disease: Identification of a Plasma Biomarker Traceable during Disease Progression. Plos One 2007, 2 (7), e647.

(58) Sturrock, A.; Laule, C.; Wyper, K.; Milner, R. A.; Decolongon, J.; Santos, R. D.; Coleman, A. J.; Carter, K.; Creighton, S.; Bechtel, N. et al. A Longitudinal Study of Magnetic Resonance Spectroscopy Huntington's Disease Biomarkers. Movement Disorders 2015, 30 (3), 393-401.

(59) Tkac, I.; Dubinsky, J. M.; Keene, C. D.; Gruetter, R.; Low, W. C. Neurochemical changes in Huntington R6/2 mouse striatum detected by in vivo $\mathrm{H}-1 \mathrm{NMR}$ spectroscopy. Journal of Neurochemistry 2007, 100 (5), 1397-1406.

(60) van den Bogaard, S. J. A.; Dumas, E. M.; Teeuwisse, W. M.; Kan, H. E.; Webb, A.; Roos, R. A. C.; van der Grond, J. Exploratory 7-Tesla magnetic resonance spectroscopy in Huntington's disease provides in vivo evidence for impaired energy metabolism. Journal of Neurology 2011, 258 (12), 2230-2239.

(61) Tkac, I.; Henry, P. G.; Zacharoff, L.; Wedel, M.; Gong, W. M.; Deelchand, D. K.; Li, T. B.; Dubinsky, J. M. Homeostatic adaptations in brain energy metabolism in mouse models of Huntington disease. Journal of Cerebral Blood Flow and Metabolism 2012, 32 (11), 1977-1988.

(62) Mochel, F.; Haller, R. G. Energy deficit in Huntington disease: why it matters. Journal of Clinical Investigation 2011, 121 (2), 493-499. 
(63) Dubinsky, J. M. Towards an Understanding of Energy Impairment in Huntington's Disease Brain. Journal of Huntingtons Disease 2017, 6 (4), 267-302.

(64) Polyzos, A. A.; Lee, D. Y.; Datta, R.; Hauser, M.; Budworth, H.; Holt, A.; Mihalik, S.; Goldschmidt, P.; Frankel, K.; Trego, K. et al. Metabolic Reprogramming in Astrocytes Distinguishes Region-Specific Neuronal Susceptibility in Huntington Mice. Cell Metabolism 2019, 29 (6), 1258-1273.

(65) Toczek, M.; Zielonka, D.; Zukowska, P.; Marcinkowski, J. T.; Slominska, E.; Isalan, M.; Smolenski, R. T.; Mielcarek, M. An impaired metabolism of nucleotides underpins a novel mechanism of cardiac remodeling leading to Huntington's disease related cardiomyopathy. Biochimica Et Biophysica Acta-Molecular Basis of Disease 2016, 1862 (11), 2147-2157.

(66) Gruber, B. M.; Klaczkow, G.; Jaworska, M.; Krzyszton-Russjan, J.; Anuszewska, E. L.; Zielonka, D.; Klimberg, A.; Marcinkowski, J. T. Huntington' disease imbalance of amino acid levels in plasma of patients and mutation carriers. Annals of Agricultural and Environmental Medicine 2013, 20 (4), 779-783.

(67) Zacharoff, L.; Tkac, I.; Song, Q.; Tang, C.; Bolan, P. J.; Mangia, S.; Henry, P.-G.; Li, T.; Dubinsky, J. M. Cortical metabolites as biomarkers in the R6/2 model of Huntington's disease. Journal of Cerebral Blood Flow and Metabolism 2012, 32 (3), 502-514.

(68) Peng, Q.; Wu, B.; Jiang, M.; Jin, J.; Hou, Z.; Zheng, J.; Zhang, J.; Duan, W. Characterization of Behavioral, Neuropathological, Brain Metabolic and Key Molecular Changes in zQ175 Knock-In Mouse Model of Huntington's Disease. Plos One 2016, 11 (2), e0148839. 
(69) Menzie, J.; Pan, C.; Prentice, H.; Wu, J.-Y. Taurine and central nervous system disorders. Amino Acids 2014, 46 (1), 31-46.

(70) Jakaria, M.; Azam, S.; Haque, M. E.; Jo, S.-H.; Uddin, M. S.; Kim, I.-S.; Choi, D.-K. Taurine and its analogs in neurological disorders: Focus on therapeutic potential and molecular mechanisms. Redox Biology 2019, 24, 101223.

(71) Tadros, M. G.; Khalifa, A. E.; Abdel-Naim, A. B.; Arafa, H. M. M. Neuroprotective effect of taurine in 3-nitropropionic acid-induced experimental animal model of Huntington's disease phenotype. Pharmacology Biochemistry and Behavior 2005, $82(3), 574-582$.

(72) Zabel, C.; Mao, L.; Woodman, B.; Rohe, M.; Wacker, M. A.; Klaere, Y.; Koppelstaetter, A.; Nebrich, G.; Klein, O.; Grams, S. et al. A Large Number of Protein Expression Changes Occur Early in Life and Precede Phenotype Onset in a Mouse Model for Huntington Disease. Molecular \& Cellular Proteomics 2009, 8 (4), 720-734.

(73) Perluigi, M.; Poon, H. F.; Maragos, W.; Pierce, W. M.; Klein, J. B.; Calabrese, V.; Cini, C.; De Marco, C.; Butterfield, D. A. Proteomic analysis of protein expression and oxidative modification in R6/2 transgenic mice. Molecular \& Cellular Proteomics 2005, 4 (12), 1849-1861.

(74) Naia, L.; Cunha-Oliveira, T.; Rodrigues, J.; Rosenstock, T. R.; Oliveira, A.; Ribeiro, M.; Carmo, C.; Oliveira-Sousa, S. I.; Duarte, A. I.; Hayden, M. R. et al. Histone Deacetylase Inhibitors Protect Against Pyruvate Dehydrogenase Dysfunction in Huntington's Disease. Journal of Neuroscience 2017, 37 (10), 2776-2794. 
